amount of distortion. Behind the spot thus selected an artificial pupil is made by the method which I have described as "optical iriclectomy," the essentials of such a pupil being that it shall be small, of V-shape, and that its base shall be at the pupillary margin and its apex towards the periphery of the iris. I need not republish here the technique of this operation; but I would not counsel anyone to undertake it until after a reasonable amount of dexterity in ophthalmic surgery and a fairly complete knowledge of the behaviour of the iris during evacuation of the aqueous humour have been gained as the result of practice. The operation is one which requires both skill and knack; but the visual results which it affords are worth all the care required in performing it. Finally, when the eye has forgotten the iridectomy, the cicatrix may be tattooed with Indian ink, and thus completely concealed from ordinary observation. 'To what extent the artificial pupil is noticeable will depend of course mainly upon the colour cf the iris.

It seems to me to be of great importance that the order of procedure above set forth should be strictly adhered to. I have seen one case in which an eye was entirely lost in the hands of a surgeon who began his treatment by an iridectomy, and then, while the iris was still irritable, cauterised the corneal surface. Intense iritis was the result, and the eye was rendered permanently useless as an organ of vision.

Pempinigus.--Only two cases presented themselves of the peculiar gradual drying up of the cornea associated with complete conjunctival atrophy, which has been described in former years as "xeroma," and which has lately been regarded (I am not quite sure whether correctly) as a form of ocular pemphigrs. Both patients were males, apparently in good health. Both were transferred to hospital, and there is nothing to record about them except that in one I tried the effect of dissecting off the atrophied conjunctiva and of replacing it by that of a rabbit. The graft united well and the progress of the corneal disease was stayed, but only for a time. As soon as the fresh conjunctiva came under the dominion of the patient's nutritive conditions it degenerated and shared the fate of his own which had preceded it. I could not claim more than that the advent of complete blindness had been delayed for a few weeks. The second case was only noteworthy as having afforded to the council of the Ophthalmological Society an opportunity of casting the ægis of their protection over the practice of meeting homoopaths in consultation, and as having therefore compelled me, as a matter of ordinary selfrespect, to withdraw from the membership of a body by which such a course was at least tacitly sanctioned.

Lead deposit. - I may pass over the single example of corneal walformation and the three instances in which keratitis was associated with rickets or with leprosy as being rare conditions of only small interest in daily practice, in order to mention the two examples of lead deposit on the cornea. Most text-books contain a word of warning against the use of lead lotions for the eyes, but they are nevertheless still occasionally prescribed. For simple conjunctivitis a solution of acetate of lead is probably quite as good as any other astringent, but it is apt to leave a scale of opaque carbonate upon any spot where the cornea has lost its epithelium. The late $\mathrm{Mr}$. Dixon was accustomed to describe how an old lady, who har been cured of ocular catarrh by a lotion of acetate of lead, put the remainder of the medicament away in a cupboard, and brought it out as a precious treasure whenever there Lappened to be a bad eye in the family or among her neighbours. The bottle soon contained a considerable sediment of carbonate of lead, and this was carefully shaken up prior to application. In hospital practice it is not at all uncommon to see lead deposits upon the cornea, but pricate patients have generally been preserved from them. In one of my cases the lead had been on the cornea for about two years, and formed a dense white central patch, the surface of which was covered by little cracks, and which from time to time set up violent irritation by acting as a foreign body. The sufferer was a middle-aged man of very quiet temperament, and he had borne this long period of misery. About once a month his eye would be actively bad for a week, and then it would quiet down again, and be only uncomfortable. The patch so covered the centre of the cornea as to block out vision. After a thorough application of cocaine I scraped away the whole of the lead, the epithelium was soon reproduced and both vision and comfort were restored. In this instance, fortunately, the lead was external to tho true corneal tissue, just beneath the epithelium, and it had done no permanent injury. When it is deposited in an ulcer of any depth its removal is much more difficult and less favourable results must be looked for. The cicatrix will probably be at least partially opaque and the curvature of the cornea will be impaired. It is all the more necessary that such risks should not be incurred; and, as all the benefits to be obtained from a lead solution may be obtained equally from the salts of zinc or of silver, there is no excuse for subjecting a patient to risk of permanent injury in the course of endeavours to relieve a comparatively trivial affection.

(To be continued.)

\section{TREATMENT OF THE NOSE AND THROAT AS A SOURCE OF MIDDLE-EAR DISEASE:}

\author{
PRECAUTIONARY SUGGESTIONS.
}

\section{BY THOMAS BARR, M.D. GLAS.}

THE extraordinary interest developed of late years in diseases of the nose and throat has led to the greatly extended use of remedies applied to those regions. Nasal irrigations, by means of the donche, syringe or simple sniffing, are not only much more frequently prescribed by medical men, but it is now no uncommon thing for patients to resort to them without medical advice or guidance. Cauterisation of the interior of the nose, by the galvanic cautery, chromic acid or other corrosive substance, has become almost the routine practice of the numerous rhinologists who now devote themselves to this region; while operations upon the nose and naso-pharynx more or less severe have become of striking frequency. That, on the whole, good to humanity has resulted from this great activity cannot be doubted. Unfortunately, however, it often happens, from the imperfection of human agency, that with improved and increased methods of treatment there is involved the danger of doing mischief The middle ear, from its intimate connexion with the nasal channels, being in fact an offshoot from these, is specially exposed to danger from energetic nasal treatment. It may therefore be useful at the present time to draw attention to this source of danger to the middle ear, and to the precautions calculated to avert such danger.

\section{NASAL IRRIGATIONS.}

I shall consider first the risks attending the use of irriga tions to the nose, such as Weber's douche, the syringe and simple sniffing. Since the case reported by Roosa of New York in 1869 of acute otitis media, followed by pyæmia caused by Weber's nasal douche, many instances of acnte purulent inflammation of the middle ear arising in this way have been placed upon record. Attention has also been drawn to this source of danger by Knapp, Elsberg; von Tröltsch, Politzer, Weber-Liel, Berthold, Guye and others. My own experience has taught me that the entrance of liquid into the middle ear through the Eustachian tube during the use of the nasal douche or syringe, is a very common occurrence. This accident is fortunately, however, by no means always followed by inflammatory mischief. Patients, especially children, frequently mention that they experience pain in the ear during the act of syringing, although no real mischief results. On the other hand, serious mischief to the ear may ensue. Purulent disease with all its possible consequences, or simple catarrh with temporary or permanent injury to the hearing, may without doubt be a consequence. While many of the cases of purulent middle-ear disease excited in this way have been mild and short in duration instances are, in my experience, not very uncommon in which the disease has assumed a persistent and eren serious character. I can recall several cases which illustrate this. A young lady who had daily for nearly a year used an alkalo-saline solution, by means of the syphon nasal douche, suddenly while in the act of using the douche became conscious of the liquid passing up into the middle ear. Intense pain in that ear was immediately experienced, followed by suppuration, perforation of the membrane and, ultimately, by caries and necrosis of the mastoid. I operated on the mastoid, and, after many months of great distress and anxiety, the purulent disease nas brought to an end, leaving behind, however, a permanertily damaged tympanum. More recently a gentleman, after the 
employment of the posterior nasal syringe by a medical man, was seized with a purulent disease of the middle ear. $\mathrm{He}$ was confident that it followed immediately after and was caused by the injection of the liquid. The purulent disease proved extremely obstinate, involving months of treatment before the secreting process was brought to an end, leaving, bowever, a permanent perforation. Still more recently a patient, whose ears had hitherto been in a sound condition, was under treatment for an affection of the nasal passages. This treatment included the use of Weber's nasal douche. Purulent disease was excited in both middle ears, which, from the manner of its onset, was clearly due to the entrance of the liquid into the middle ears. The suppuration assumed a most persistent character, and the perforations increased so as to involve a large part of each membrane. Serious deafness ensued, and ultimately, after the use of many different methods of treatment, the secreting process was brought to an end, leaving behind large perforations.

What are the conditions which favour the entrance of liquid into the middle ear during the use of the syringe or douche? Structural peculiarities in the nasal passages and Eustachian tube, existing naturally or induced by disease, are probably the most important factors. In children, for example, owing to the smallness of the naso-pharyngeal space, the width and shortness of the Eustachian tubes, their limited control over the muscles of deglutition, there is more likelihood of liquid injected into the nasal passages finding its way into the middle ear. Likewise in adults, whose Eustachian tubes have been rendered abnormally patent by atrophy of the mucous membrane, or where the nuscular mechanism of the Eustachian tube has been impaired, the resistance to the passage of air or liquid is much diminished. In those conditions liquids injected into the nasal passages or drawn in by the patients, however carefully, are apt to find their way into the tympanic cavity. In one of the cases just referred to there was marked imperfection in the due and firm closure of the Eustachian tubes. Of these structural peculiarities, however, the partial or complete impermeability of one or other nasal passage or of the cavity of the naso-pharynx is the most fruitful source of accident. Such impermeability is common, and may be due to deflection, exostosis, or enchondrosis of the septum, to hypertrophic or other swelling of the turbinated bodies, or to postnasal growths. When one of the nasal passages is thus closed and liquid is injected into the opposite nasal passage by a syringe, the nozzle of which fits tightly into the orifice of the nose, a passage of liquid into the middle ear will be an almost certain result. ${ }^{1}$ The employment of strong force, either from too great height of fall in the case of Weber's douche or from excessive pressure upon the piston in ordinary syringing, is always improper, but is especially mischievous when there exists any of those forms of obstruction. It is to be carefully noted that in any case, even when no structural peculiarity exists and when the syringe is used with every caution, the performance of the act of swallowing during the passage of the fluid through the nasal passages greatly favours the entrance of the liquid into the middle ear. Another danger is that the liquid still remaining in the crevices of the naso-pharynx, shortly after the injection, is often impelled into the middle ear if the patient blows the nose vehemently or sneezes. ${ }^{2}$

I have said that liquid frequently finds its way into the middle ear without any injurious effects. What are the circumstances which determine injury when liquid finds its way into the middle ear? A middle ear predisposed to inflammation, either through hereditary tendency, a past attack or a present chronic disease, is of course much more apt to be injured by the entrance of the liquid. The force by which the liquid is propelled into the ear must to some extent determine the effect. The character of the fluid, however, especially in regard to temperature, strength and purity, is a still more important factor. A proper degree of warmth is essential to safety : we know that cold liquids injected into the ear through the external auditory canal are apt to prove injurious; they must prove at least equally injurious when forced through the Eustachian tube. The habit of drawing or sniffing cold water into the nasal passages, indulged in by some persons with the idea of curing or preventing cold in the head, is probably responsible for a number of middle-ear inflammations. This method of irrigating the nose is no doubt often mischievous, especially where the Eustachian tubes are abnormally permeable. ${ }^{3}$ Irritating solutions finding their way into the middle ear must of course be more likely to excite inflammation than those of a mild character. The rôle played by mucus, pus or blood forced from the naso-pharynx into the middle ear is not easily determined, although when accompanied by pathogenic organisms, such as those peculiar to ozæna, diphtheria, scarlet fever and certain forms of nasal catarrh, they must prove most important sources of mischief. When a combination of all these conditions and causes exists in the one case the danger to the middle ear must be great, if not unavoidable, and it is probable that such a combination not unfrequently exists.

\section{The Galvanic Cautery and Corrosive Substanchs.}

Let us now consider to what extent the galvanic cautery and corrosive substances-such as chromic acid-are responsible for the production of mischief in the middle ear. Exciting as they do more or less inflammation in the tissues of the nose, it would not be surprising if extension to the middle ear sometimes took place. I believe, however, that such mischief, when it does occur, is frequently due to the neglect of certain precautions after the cauterisation. These applications being usually made in the doctor's house, exposure to the airtravelling, it may be, to a distant part-tends to increase the irritation and leads to its extension from, say, the inferior turbinated body, to the Eustachian tube immediately behind. The following case illustrating this came lately under my observation. The left nasal passage of a lady was cauterised with the galvanic cautery in London on the day following she travelled to Glasgow, feeling as if she had a severe cold in the head with violent sneezing. On the day after her arrival in Glasgow she was seized with severe pain and throbbing in the ear corresponding with the side which had been cauterised. When I saw her a week afterwards she suffered from acute otitis media on the left side, with implication of the mastoid, which, in the region behind the ear and in the posterior wall of the auditory canal, was bulging and painful; neither discharge nor perforation had taken place, but the hearing power was almost abolished in that car. After leeching the mastoid and incising the posterior wall of the external auditory canal, with only temporary benefit, it was proposed to perforate the mastoid behind the auricle, but, after consultation, it was decided, owing to the subsidence during the previous twenty-four hours of the pain over the mastoid, to postpone the operation. The hearing began to improve and the bulging of the posterior wall of the canal gradually diminished, with vltimate but very slow recovery. In this case I do not think that one would be justified in positively asserting that the cauterisation was the direct cause of this middle-ear mischief, although the order of events-the cauterisation followed by the nasal irritation, then by the pain in the corresponding ear-would lead one to suspect that the operation on the nose had something to do with what followed. Syringing the nose after cauterisation, when the passage is obstructed from swelling, is apt to force liquid into the middle ear and thus excite mischief. Probably the intro. duction of micro-organisms along with the applications, such as when the part of the electric cautery near to the burner has been imperfectly cleaned and disinfected, may be the means of exciting suppurative inflammation in the midrle ear. When the cautery is applied near to the mouth of the Eustachian tube the danger is of course greater. Hence cauterisation of the naso-pharyn $x$ is particularly apt to injure the middle ear, as recorded cases prove. Galvanic cauterisation of the pharynx granular pharyngitis may likewise be followed by acute purulent inflammation of the middle ear. Such a case is within my knowledge. Gruber also remarked at the meeting of the British Medical Association in Nottingham that the galvanic cauterisation of the wall of the pharynx may, by injury to the muscular fibres beneath, damage the muscular mechanism of the tube. In regard to the use of chromic acid I have not yet seen a case of middle-ear mischief from the use of this corrosive, but, judging from the irritation and swelling of the mucous membrane usually produced by this substance, implications of the middle ear might occasionally be expected. In a paper by Eitelberg* there are descriptions of cases of troublesome middle-ear suppuration excited by chromic acid applied to the nasal mucons membrane. When the galvanic cautery or chromic acid has to be applied to the nasal mucous membrane too great care cannot be enjoined upon the patient to avoid exposure to cold.

3 Eitelberg in Wiener Medicinische Presse, June 7th, 1891. 4 Ibid. 
OPERATIONS ON NOSE AND THROAT.

Let us now consider to what extent the greatly extencled use of operations on the nose and naso-pharynx may be regarded as a source of mischief to the adjoining cavity of the middle ear. The removal of adenoid vegetations from the naso-pharynx has become of late years one of the commonest of operations. As an operation most frequently performed in cases of defective hearing I have had very considerable experience of it. While I have no doubt seen a consideraile number of cases in which, after the removal of these growths, a purulent inflammation affected one or both middle ears, I have not had experience of any case in which this assumed a serious character-none so serious as we have seen to happen after the nasal douche. I observe, however, that Dr. Gorham Bacon, at the twenty-fifth annual meeting of the American Otological Society, describes a case in which inflammation of the mastoid cells and periosteal abscess followed upon the operative removal of these vegetations. I have, however, seen at least one case in which permanent aggravation of deafness followed this operation, where a chronic adhesive catarrh of the middle ear existed. I think in this form of deafness we should be very cautious in operating upon the naso-pharynx or nasal passages. While the ordinary exudative catarrh may be very much benefited in this way, there is no doubt a fear of doing more harm than good in these adhesive or hypertrophic forms of catarrh. Most aural surgeons have seen cases of inflammation of the middle ear following the removal of tonsils and nasal polypi. The extent to which operations upon the nasal septum and turbinated bodies and the forcible mechanical distension of the nasal passage by instruments constructed on the principle of the glove stretcher, so frequently performed of late years, affect the middle ear prejudicially has not yet come to light. Eitelberg describes an obstinate suppuration of the middle ear following the removal of the posterior end of the inferior turbinated body. It is fitting also to refer here to the possibility of exciting inflammation of the middle ear in cases where the posterior nares have been plugged in consequence of bleeding from the nose. ${ }^{5}$ Serious mischief has arisen in such cases from the retention of the plugs too long and the production thereby of septic inflammation in the middle ear. One case of death is reported from this cause, owing to cerebral complication. In considering the liability of the middle ear to receive injury from any of these forms of nasal treatment, it is to be remembered that here, as in all organs of the body where the vulnerability of the organ is increased by hereditary weakness and by previous or existing disease, the action of $a_{i}$ local cause, be it the entrance of liquid into the ear or the production in the neighbourhood of the middle ear of inflammatory irritation or septic mischief, is fraught with the greatest danger. I would venture to urge upon rhinologists the importance of giving due attention to these considerations when treating the nasal regions. Do not order the nasal douche without considering the possible effects upon the middle ear, especially where an old inflammatory disease or a marked tendency to deafness already exists. Do not hold out vain hopes to persons suffering from incurable deafness that cauterisation of the inferior turbinated body, the removal of a tonsil, perhaps only slightly enlarged, or of a vegetation in the naso-pharynx, will restore or improve the hearing. Instead of improvement the very opposite result may follow. I have had patients coming to me, suffering from incurable sclerosis of the middle earf and labyrinthine mischief, who were encouraged to expect great improvement of the hearing if such operative measures were submitted to; such expectations being held out without even the preliminary precaution of examining the ear. It is not surprising that the effect of such treatment is often to increase rather than to improve the deafness. It is a great mistake to conclude in such forms of deainess that if a deflection of the septum or a degree of hypertionhy of the inferior turbinated body exists, operative measures should immediately be adopted. Even when some adenoid growths exist in the naso-pharynx, in sclerosis or adhesive catarrh of the middle ear, it is a question for serious consideration whether operative interference with these growths may not excite an increase in the morbid process in the ear, instead of benefiting them. I cannot do better than here quote from the recent work of my friend, Dr. McBride. He says: "If ten persons who, in answer to leading questions, state positively that they are not in any way troubled by symptoms referable to their nose be examined the probability is that more than half will show such evidence of disease-c.g., spines on the septum, thickening of the mucosa over the turbinated bodies \&c. - as would lead to severe operative mensures being advised by many rhinologists if they were to carry out what they advocate. This excessive operative zeal appears to me to be a great danger threatening as it does the credit of our profession as a whole, and rhinology in particular. Recently an authority is re ported (wrongly reported, I trust) to have stated before a medical society in America that he cured diseases of the internal ear by operating on the nose, and his remarks do not seem to have excited laughter. I have dwelt perhaps unduly on these points, but the practical outcome I desire to lead up to is this: let no surgeon be induced to operate on the nose simply because there is some degree of hypertrophy of the mucosa unless the symptoms are sufficiently important to warrant such interference."

\section{Precautionary Suggegtions.}

I shall now state as concisely as possible the precautions which to my mind should be kept in view when treating the nasal passages and naso-pharynx, in order to avoid or diminish the risk of exciting disease in the middle ear. 1. Patients before using the nasal syringe, Weber's douche or the hand douche, should be carefully instructed by the surgeon in their proper and safe use. 2. Previous to injecting fluids by the syringe or Weber's douche into the nose, or prescribing such, the nasal passages should be carefully examined, and if one should be found obstructed the fluid should be injected into the obstructed passage. 3. The nozzle of the syringe should not tightly close the nostril and during the injection of the fluid the stream should be frequently interrupted 4. If a syringe is employed, too great force must not be used, especially if there be resistance to the flow of the fluid from one nostril to the other ; if Weber's douche is employed the fall must not be too great-not more than two feet. 5 . The fluid injected should always be comfortably warmed-say $80^{\circ}$ to $90^{\circ} \mathrm{F}$ - - and it should hold in solution a saline, such as a 1 per cent. solution of common salt or bicarbonate of soda, while in ozæna or other bacterial diseases a definite antiseptic should be employed. 6 . The act of swallowing must carefully be avoided during the douche ; this is aided by breathing: through the mouth. Eitelberg suggests that the patient should protrude the tongue so as effectually to prevent the act of swallowing. 7. In the case of infants or very young children, or in adults whose Eustachian tubes are abnormally permeable, the syringe or Weber's douche should not be employed. The liquid should in these cases be poured into the nasal passages with a spoon or other suitable appli. ance while the patient (if old enough) should sound the rowel "a." 8. The patient should not blow his nose or, if possible, sneeze for at least fifteen minutes after; he should be instructed that in the event of the liquid entering the ear, he must swallow several times with the nostrils closed. 9. After operations on the nose or naso-pharynx, or the use of corrosive substances which may produce swelling or obstruction, the syringe should be avoided or used with great caution, for few days, during which the patient should be careful toavoid exposure to cold or septic influences. 10. In operations or canterisation great care should be taken to secure cleanliness and an aseptic condition of the instruments or appliances used. If the finger-nail is employed to scrape away vegetations there is obviously special need for precautions in these directions. Glasgow.

\section{ON THE DIAGNOSIS OF THE DIFFERENT FORMS OF PROSTATIC ENLARGEMENT.}

By C. MANSELL MOULLIN, F.R.C.S.ENG SURGEON TO THE LONDON HOSPITAL.

ONE of the natural results of the recent adrances in the surgical treatment of enlargement of the prostate is the demand for a higher degree of accuracy in the diagnosis of the different forms assumed by the growth. So long as passing a catheter at longer or shorter intervals was the only method for giving relief exact measurements were not of much consequence. Then the chief question was the amount of residual urine and the number of times the patient was disturbed in the twenty-four hours; the growth might extend backwards towards the rectum or upwards into the bladder or it might spread into the walls of the urethra and compress the passage into a narrow slit. So long as it did not obstruct 